\title{
UMA LEITURA SOBRE A HIPÓTESE CRIOULÍSTICA DO PORTUGUÊS DO BRASIL
}

\author{
Juciele Pereira Dias
}

\begin{abstract}
RESUMO ${ }^{\circledR}$ : No presente trabalho objetivamos observar como Joaquim Mattoso Câmara Jr. deixa em seu discurso traços que apontam para uma discordância em relação a uma Hipótese do Português Crioulo no Brasil. Concomitantemente, buscamos fazer uma leitura de um artigo de Carson, escrito uma década após as reflexões de Mattoso, em que, sem fazer referência ao autor, consolida uma posição em relação à hipótese crioulística que, mesmo em diferentes condições de produção, vai ao encontro das reflexões do lingüista.
\end{abstract}

PALAVRAS-CHAVE: História das Idéias Lingüísticas, Mattoso Câmara, Neusa Carson.

\section{INTRODUÇÃO}

Após a época das grandes descobertas territoriais, tivemos um período de colonização que, no caso do Brasil, houve a chegada de uma nova língua a um espaço lingüísticocultural desconhecido pelo ocidente. A Língua Portuguesa, trazida pela expansão ultramarítima de Portugal (séc. XV-XI), instituiu movimentos de memória, deslizamentos lingüísticos, os quais, ao longo da história, foram observados por teóricos da linguagem. A busca por um estudo aprofundado da Língua Portuguesa no/do Brasil levou muitos desses estudiosos a se preocuparem com a descrição e análise da referida língua, da mesma forma que de outras línguas presentes no nosso território, como as línguas indígenas, as línguas africanas; as línguas vindas do continente europeu, como o Italiano, o Alemão, o próprio Português, entre outras.

Esse trabalho, em torno da diversidade lingüística no país, ocorreu devido ao fato de que, para tal descrição e análise, os pesquisadores se lançavam em um estudo não somente da língua que estavam trabalhando, mas também analisavam se havia "influências" de outras línguas em

\footnotetext{
(c) Trabalho desenvolvido a partir do projeto Lingüística no Sul: estudos das idéias e organização da memória dos anos $\mathbf{8 0}$ a 2000 sob orientação da prof ${ }^{\mathrm{a}}$ Dr. Amanda Eloina Scherer.
}

funcionamento no ambiente lingüístico-cultural em que os sujeitos observados estavam imersos. Dentre os pesquisadores em línguas que se destacaram no cenário Nacional, temos o teórico Joaquim Mattoso Câmara Jr. como um importante lingüista brasileiro a se interessar sobre esse tema. No início da década de 40, o autor publicou a obra Princípios de Lingüística Geral, bem como outros textos e artigos específicos sobre análise, descrição e estrutura da língua portuguesa.

Em um artigo intitulado Línguas européias de ultramar: o português do Brasil, que teve primeira versão em alemão no ano de 1963, o estudioso faz observações sobre a relação do nosso português com línguas indígenas e africanas bem como faz reflexões sobre uma "hipótese crioulística" do Português do Brasil. Sobre esse trabalho, Tânia Alkmim (2005, p.105) afirma que o lingüista "tenta mostrar que tal hipótese representa uma contribuição inovadora para 0 debate da questão do português brasileiro".

O estudo acerca da hipótese crioulística também foi realizado por uma lingüista santamariense, Neusa Martins Carson, uma das primeiras lingüistas do Rio Grande do Sul e que teve sua produção voltada para o trabalho em descrição de línguas. A história e a produção de Carson foram objetos de nossa pesquisa em iniciação científica, ao longo do ano de 2006, o que nos leva a observar que a estudiosa foi leitora e aluna de Joaquim Mattoso Câmara Jr. Além disso, na década seguinte à publicação do referido artigo do lingüista, no ano de 1979, na Revista do Centro de Artes de Letras, Carson publicou um artigo intitulado O Português do Brasil: um Crioulo?. Neste, a pesquisadora aponta para o fato de alguns traços morfossintáticos da língua portuguesa, considerados por estudiosos como influências de línguas africanas, serem nada mais do que constituintes da estrutura lingüística da Língua Portuguesa, os quas já estavam presentes no português arcaico do século XVI.

Por conseguinte, o que propomos para este trabalho é observar como um lingüista, 
em um período ainda muito próximo às discussões sobre uma possível hipótese crioulística, começa a deixar em seu discurso traços que apontam para uma discordância em relação à referida hipótese. Além disso, pela leitura do artigo de Carson, escrito uma década após as reflexões de Mattoso Câmara, observamos que, sem fazer referência ao autor, a lingüista faz questionamentos, e, por fim, consolida uma posição em relação à hipótese crioulística que, mesmo em diferentes condições de produção, vai ao encontro das reflexões do lingüista.

\section{Uma breve leitura de Línguas européias de ultramar: o português do Brasil, de Joaquim Mattoso Câmara Jr.}

O artigo Línguas européias de ultramar: o português do Brasil, de Joaquim Mattoso Câmara Jr., no qual são feitas observações sobre a hipótese de, no Brasil, ter existido um Português crioulo, resulta de uma palestra do lingüista, pronunciada na Universidade de Bonn, em 1963. Nesta época, Mattoso Câmara juntamente com outros lingüistas, buscava consolidar a disciplina Lingüística nos cursos de Letras do Brasil, já que, em dezembro de 1962, segundo Uchôa (2004, p.16), “o Conselho Federal de Educação estabeleceu que toda escola superior deveria incluir obrigatoriamente o ensino de Lingüística nos seus currículos". Devido a esse acontecimento, "em seu contexto de atualidade e no espaço de memória que ele convoca" (Pêcheux, 1990, p.17), é possível observarmos que Mattoso Câmara, constituía um espaço no meio acadêmico, o qual era formalizado pela institucionalização da Lingüística como disciplina obrigatória. Nesse sentido, o lingüista brasileiro participava de importantes eventos, nacionais e internacionais, no intuito de fortalecer os estudos em torno da ciência Lingüística no país.

Em relação ao artigo de Mattoso Câmara, colocamos que ele é iniciado com uma breve consideração histórica e teórica sobre a transplantação de línguas, os movimentos migratórios e é seguido de uma comparação sutil entre "as línguas européias levadas para outros continentes" (Mattoso Câmara, 1963, p.113) e "o florescimento da língua grega fora da Grécia, nas colônias itálicas e da Ásia Menor" (idem, p.113), sobre o qual o lingüista observa que "temos, pelo menos, lá como cá o sentimento coletivo de uma unidade lingüística complementada pelo de uma unidade cultural" (idem, p.113). Tais observações introduzem a questão de haver diferentes problemas em torno da antiga língua grega em relação à imposição de um ideal de língua na Europa, que segundo Mattoso Câmara (1963, p.114), "é apresentado como língua nacional 1 considerada a única língua legítima 2". Sendo assim, observamos a seguinte afirmação.

Essa maneira de interpretar o fenômeno lingüístico e de conceituar a língua trouxe uma conseqüência importante quando, pela colonização de ultramar, se criaram fora da Europa comunidades de língua européia. A língua colonial era vista, da mesma sorte que os dialetos do território da metrópole, como modalidades espúrias de dizer, fruto e índice de ignorância e bruteza. Tanto na metrópole como nas colônias a língua standard é que se visava através da educação e do refinamento do trato social. (Mattoso Câmara, 1963, p.114).

Esse apontamento do lingüista, em torno de uma língua imposta e idealizada, é intensificado quando Mattoso Câmara coloca que, após a independência das colônias em relação às metrópoles, "criou-se uma situação de certa complexidade doutrinária em matéria de língua" (idem, p.114). Acerca desta, no caso do Brasil, para Mattoso Câmara, o que interessa no momento é salientar "a atitude dos gramáticos e filósofos oficiais" (idem, p.114) de "separar o conjunto dos elementos culturais da nova nacionalidade e tentar manter para ela a norma metropolitana" (idem, p.114).

Pelo percurso das palavras desse teórico brasileiro, é possível salientarmos as marcas da sua história, as marcas de um período em que literatos, gramáticos, filólogos tinham um lugar instituído nas Universidades, eram catedráticos, reconhecidos e ouvidos, enquanto que o lingüista não tinha um lugar próprio, nem o reconhecimento dito "oficial", ou seja, segundo Altman (1998, p.106), Mattoso Câmara "era relegado à marginalidade". Como já observamos anteriormente, somente a partir dessa época da escritura do artigo, a Lingüística assume um caráter oficial, visto que estava sendo institucionalizada como disciplina obrigatória, o que entendemos ter sido um passo decisivo para sua consolidação no país e para que se constituísse a possibilidade de que lingüista

\footnotetext{
1 Grifo do autor.

2 Idem ao 1.
} 
Mattoso Câmara tivesse um lugar instituído na academia.

Pela história de um estudioso com um longo percurso em estudos sobre língua e a "nova autoridade de um lingüista", é que, nos seguintes parágrafos do texto, Mattoso Câmara dedica um espaço para considerações, tanto positivas quanto negativas, em relação às contribuições de alguns "estudiosos oficiais" que marcaram a história da nossa língua portuguesa. Dentre esses estão Mario Barreto, Rui Barbosa, Visconde de Pedra Branca, Macedo Soares, José Jorge Paranhos da Silva, Batista Caetano, Renato Mendonça, Rufino José Cuervo. Enfim, ao longo de uma incansável abordagem em torno de tais nomes, o lingüista vai introduzindo a temática "que respeita à influência de um substrato indígena e um substrato africano no Português do Brasil" (idem, p.116).

Acerca das línguas indígenas, temos a afirmação a seguir.

\begin{abstract}
As línguas indígenas constituem um complexo conjunto de sistemas muito diversos tanto genética como tipologicamente, e até agora foram muito pouco estudadas e sempre de maneira muito defeituosa. [...] Em relação à influência lata das línguas indígenas nos meios caboclos a que me referi há pouco, ela pode ter dado sob o aspecto de empréstimos" (Mattoso Câmara, 1963, p.116)
\end{abstract}

Ao pensar na relação entre as línguas indígenas e a língua portuguesa, Mattoso Câmara desconsidera a possibilidade de influência da primeira sobre a estrutura da segunda. O lingüista aponta para o fato de "Indígenas das mais diversas proveniências étnicas e das mais diferentes línguas terem adotado a língua geral no seu processo de aculturação" (idem, p.117) e salienta que, ainda nos anos 60, em certos pontos da Amazônia, famílias indígenas como Aruak e Karib falavam uma "língua de intercurso", com o nome de nheengatu (língua boa), cuja finalidade seria a de servir como meio de comunicação entre diferentes famílias étnicas e lingüísticas.

Já com relação às línguas africanas, o lingüista coloca que "a situação foi diferente. Os escravos negros adaptaram-se ao Português sob a forma de um falar crioulo" (idem, p.117). A relação entre as línguas africanas e a língua portuguesa do Brasil é ilustrada por Mattoso Câmara da seguinte forma:

Nos latifúndios, ou fazendas, da época colonial e do Império o contato dos senhores brancos com seus escravos negros foi intenso e estreito. As crianças eram confiadas aos cuidados das amas escravas, as chamadas "mães pretas", e devem ter tomado de início, sem sentir, elementos do português crioulo que elas usavam. (Mattoso Câmara, 1963, p.117).

A respeito das palavras de Mattoso Câmara, é possível apontarmos dois momentos da relação entre línguas. Um primeiro momento, em que os escravos negros, com suas línguas africanas, entraram em um intenso e estreito contato com a língua portuguesa do Brasil e constituíram-se linguisticamente sob a forma de um falar crioulo. E um segundo momento, que esses falantes de um português crioulo mantiveram o contato com as famílias dos senhores brancos que, por sua vez, tomaram para a língua elementos da fala dos criados.

A expressão sem sentir, utilizada pelo lingüista, evidencia que os falantes foram levados pela relação entre tais línguas, o que desencadeou movimentos lingüísticos decorrentes do contato desses falantes em um ambiente lingüístico-cultural diversificado. Diante disso, Mattoso Câmara faz a seguinte consideração: "É claro, entretanto, que não se dariam mudanças fonológicas e gramaticais profundas sem correspondência com as próprias tendências estruturais da língua portuguesa".

Esta observação nos leva ao entendimento de que o lingüista determina dois pontos: os escravos negros, inicialmente, constituíram-se sob a forma de um português crioulo, porém, na língua portuguesa, em sua totalidade, não houve mudanças significativas que já não estivessem predispostas a serem desenvolvidas pela/na língua. Um exemplo lançado por Mattoso Câmara é o uso do pronome ele como sujeito e como acusativo. Este, para o lingüista, trata-se de "uma inovação que estava prefigurada no sistema gramatical português e que no Brasil, em novas condições lingüísticas - estruturais e sociais -, encontrou um ambiente favorável para se desenvolver". (p.118)

Ao longo do texto, Mattoso Câmara afirma que a tese de que se teve uma nova língua no ambiente americano é falsa. De acordo com o teórico, "a influência do 
português crioulo, de que em princípio não se pode abrir mão, só pode ser encarado como efeito de gatilho". O que nos leva a entender a preocupação do lingüista, voltada para salientar que o Português crioulo, em relação à língua portuguesa no Brasil, não ocasionou a constituição de uma nova língua, mas sim possibilitou que essa língua se movimentasse no novo ambiente, a partir da relação com outras línguas e culturas.

Ainda Mattoso Câmara (1963, p.118) considera que "a própria evolução interna da língua, segregada noutro meio, pode determinar, entretanto, a formação de uma verdadeira língua nova", mas quanto a isso, de acordo com o lingüista, restaria saber se "as línguas européias, transplantadas por colonização, passaram, estão em vias de passar, ou passarão fatalmente a novas línguas" (idem, p.118). Logo, o teórico passa a desenvolver uma reflexão em torno da idéia de unidade lingüística e começa, a partir de leituras de Antoine Meillet, apontando a afirmação de que "nenhum falante brasileiro tem consciência de falar uma língua distinta em face do português europeu" (Mattoso Câmara, 1963, p.119). Isto o lingüista entende como sendo um sentimento de unidade que está no falante. Observamos a citação a seguir, que ilustra o pensamento do teórico em torno de tais colocações.

\begin{abstract}
O caso do espanhol é precioso, para a nossa tese, pois o brasileiro acompanha e entende, de maneira geral, o que lhe é dito, aceitando a diferença lingüística como a natural conseqüência de se tratar de outra língua, ao passo que a diferença lingüística do português europeu o impressiona como uma excentricidade dentro da mesma língua. (Mattoso Câmara, 1963, p.119)
\end{abstract}

Diante de tais reflexões, Mattoso Câmara retoma a discussão de que "é preciso reformular o problema da língua nacional" (idem, p.119). O lingüista, que foi aluno de Roman Jakobson ${ }^{3}$, defende que a língua é um organismo dinâmico e que "uma língua nunca se acha fixada e não há língua unitária e rígida" (idem, p.119).

\footnotetext{
3 O autor [Mattoso Câmara] foi influenciado a princípio pela escola francesa de lingüística, através de George Millardet, professor visitante na Universidade do Distrito Federal. Mais tarde, ele estudou nos Estados Unidos sob a orientação de Roman Jakobson e Louis Gray. (Mattoso Câmara, p. 50, 1976)

Sendo assim, nosso teórico da língua finaliza 0 artigo apresentando considerações acerca do desenvolvimento da língua portuguesa no Brasil e conclui que "a língua escrita brasileira mantém apreciável ligação com a de Portugal, afirmando-se, não obstante, certa autonomia para não perder de todo o contato com a realidade oral" (Mattoso Câmara, 1963, p.126).

\section{Uma breve leitura de Português do Brasil: um Crioulo?, de Neusa Martins Carson}

$\mathrm{Na}$ década seguinte à publicação de Joaquim Mattoso Câmara Jr., a professora de lingüística Neusa Martins Carson, da Universidade Federal de Santa Maria, que já havia sido aluna do referido professor, em 1968, num curso de verão 4 , escreveu o artigo intitulado 0 Português do Brasil um Crioulo?. Neste, em sua análise, focaliza o contato de línguas africanas com o Português e observa discordâncias e possibilidades em torno da Hipótese crioulística. O trabalho foi publicado na Revista do Centro de Artes de Letras, no ano de 1979, época em que além docente do curso de Letras na UFSM, a referida professora também ministrava aula no curso de pós-graduação em Letras da Pontifícia Universidade Católica do Rio Grande do Sul (PUCRS).

No texto, Carson começa colocando que, com a extinção do tráfico de escravos e da escravidão no Brasil, ao final do século XIX, "diversos autores, influenciados por idéias anticolonialistas, empenharam-se na investigação das origens sociais e étnicas do elemento humano" brasileiro (Carson, 1979, p.118). Tais estudos sobre a formação do novo país, de acordo com a pesquisadora, persistiram até a década de 30 do século seguinte e muitos desses trabalhos desenvolvidos, "demonstraram a interação e o caldeamento das raças branca, do colonizador, índia, do aborígine, e negra, do trabalhador escravo" (idem, p.118). Essa diversidade étnica, salientada pela lingüista, direciona para 0 objetivo do trabalho que é analisar dados lingüísticos na obra de alguns autores 5 e

4 A professora Neusa Martins Carson foi aluna de Joaquim Mattoso Câmara no I Instituto Brasileiro de Lingüística ocorrido no verão de 1967/1968, na Pontifícia Universidade Católica do Rio Grande do Sul (PUC/RS).

5 A autora não explicita quais os autores que analisará, apenas faz, inicialmente, a observação de que estarão no período compreendido entre o fim do século XIX até meados do século $X X$, bem como que os dados relevantes do trabalho foram obtidos de fontes artísticas e 
focalizar as línguas africanas em contato com o português, com a finalidade de apontar os resultados lingüísticos de tal relação.

Sendo assim, a lingüista começa suas reflexões por uma ilustração estatística, a partir do censo de 1817 , sobre a distribuição populacional que constituía o Brasil, do período posterior ao descobrimento do nosso país, em que os portugueses começaram a trazer escravos negros, para trabalharem na nova colônia, conforme podemos observar a seguir.

$\begin{array}{ll}\text { População branca__ } & 1.043 .000 \\ \text { Índios___ } & 700.000 \\ \text { Escravos negros e mulatos__ } & 2.074 .900\end{array}$

A partir da observação dos dados, em que temos uma significativa quantidade de escravos e mulatos no país, Carson (1979) afirma que tais números não bastam "para que formulemos a hipótese de que o falar dos brasileiros deve ter-se impregnado de influências do falar dos escravos" (p.118). Logo, na seqüência, temos a colocação de que "as mães mais severas da época não puderam evitar o contato entre os seus filhos e os de suas babás ou cozinheiras; ou que estas the trouxessem termos culinários" (idem, p.118).

Outro fato observado, em torno dessa relação de línguas em contato, é que "os senhores de escravos procuravam adquirir escravos de tribos diferentes, para que não pudessem tramar golpes contra seus senhores" (idem, 1979, p.119). Devido a tal diversidade lingüística, constituída de diferentes tribos e, consequentemente, de diferentes línguas, havia formas próprias para designar os falantes de origem africana, em função do estado de sua língua. De acordo com Carson (1979), "os chamados 'negros novos', aqueles recém chegados ao Brasil, falavam apenas sua própria língua; e os 'landinos' eram os que já falavam o Português ao chegarem" (p.119).

A partir dessas colocações, observamos que não temos referência a uma designação para falante de "Português crioulo", podendo ter sido desconsiderada essa forma de falar e, pode até mesmo ter sido evitada em função do prestígio que tinham os falantes da Língua Portuguesa. Ou ainda do prestígio da própria Língua Portuguesa, objeto muitas vezes a ser

literárias como canções populares, diálogos de romances, documentos legais etc. alcançado por falantes de outras línguas presentes nesse espaço lingüístico-cultural, pois havia, nessa época, numerosos grupos lingüísticos de origem africana, que conforme apresenta Neusa Carson (1979, p.119), "as principais famílias representadas no Brasil colonial são a Niger-Kordafânia, mais numerosa, e a Afro-Asiática".

A abordagem histórica, discorrida por Neusa Carson no texto, aliada à sua formação em descrição lingüística, evidencia que essa estudiosa possui um denso conhecimento da organização das comunidades africanas presentes no território brasileiro. Isto sustenta os apontamentos da pesquisadora em torno do fato de que algumas línguas africanas eram usadas como "línguas francas" entre os escravos. Como exemplo disso, a lingüista salienta que "a língua Yorubá, também conhecida na Bahia como Nangô, ou Gegênagô, tornou-se a língua franca" (Carson, 1979, p.120) que possibilitou, "por longo tempo após término da escravidão, os laços culturais e comerciais entre Bahia e Lagos, Nigéria" (Carson, 1979, p.120). Mesmo tendo a língua portuguesa como a língua para a comunicação diária, o Yorubá, de acordo com Carson (1979, p.120) "é a língua usada nos 'terreiros' mais tradicionais pelos 'pais-de-santo' e 'mães-desanto' na Bahia, na invocação de seus santos ou 'orixás'”. A pesquisadora coloca a possibilidade de que, no Brasil, tenham se desenvolvido "falares de emergência", e que esses poderiam "ter se mesclado com o Português, que era aprendido de modo simplificado pelos escravos para que pudessem comunicar-se com seus senhores". (Carson, 1979, p.121).

A preocupação central da estudiosa, em seu trabalho, é contrapor a possibilidade de uma idéia de que as línguas africanas teriam alterado a estrutura da Língua Portuguesa no/do Brasil, em especial a língua de falantes de classes menos privilegiadas, ao contato com uma normatividade lingüística instituída como oficial. Em torno disso, observamos, a seguir, as palavras da pesquisadora.

\begin{abstract}
Ainda hoje é comum fazer-se referência a um linguajar das camadas menos instruídas da população, da forma e função simplificadas, como sendo 'fala de negro'. Na realidade, o uso de tais formas não se restringe apenas a pessoas de cor, mas pode ser encontrado entre brancos, índios, mulatos e mestiços de classes sociais rurais menos aquinhoadas. Existem vários trabalhos de pesquisadores, especialmente estrangeiros, que afirmam
\end{abstract}


existir falar Crioulo no Brasil [...]. (Carson, 1979, p.121).

Para fundamentar a sua posição contrária a uma possível influência de um falar Crioulo na Língua Portuguesa, a lingüista traz exemplos do falar popular brasileiro anterior à presença de línguas africanas. Muitos estudiosos apontaram mudanças fonológicas, gramaticais e de vocabulário como "típicos brasileirismos", entretanto Carson (1979, p.121) observa que "às vezes somos surpreendidos por formas consideradas caipirismos e que não são senão arcaísmos dos séculos XV e XVI". Como ilustração e uma breve análise, a pesquisadora coloca alguns exemplos em que se tem a perda do marcador de terceira pessoa do plural, a ausência da concordância de gênero, construções em que - grau de adjetivo é feito por construção sintática, como em mais grande. Uma das colocações, utilizadas no trabalho, é um enunciado de Fernão Lopes do século XVI: "e quando ele entrou viu ela e seus corregimentos assim dispostos", a partir do qual Carson afirma que deslocamentos morfossintáticos, como o exemplo do pronome ele, já apareciam na literatura portuguesa arcaica e que não seriam evidências de um falar crioulo.

A pesquisadora, após discorrer sua análise em defesa de que não há evidências de que o contato das línguas africanas com o Português tenha provocado uma forte alteração na Língua Portuguesa, finaliza seu trabalho observando que "existem, de fato, numerosos vocábulos de origem africana no português, especialmente em áreas culturais da culinária, religião e instrumentos musicais" (Carson, 1979, p.123). Além disso, na sua posição contrária a presença de um falar crioulo no país, Neusa Carson afirma que tivemos o uso de línguas francas africanas, as quais, possivelmente, teriam bloqueado 0 surgimento de um Português pidinizado que, por sua vez, pudesse vir a constituir um Português crioulizado.

\section{Reflexões a partir de uma leitura em torno da Hipótese Crioulística}

Após a leitura dos artigos Línguas européias de ultramar: o português do Brasil, de Joaquim Mattoso Câmara Jr. e Português Crioulo?, de Neusa Martins Carson, buscamos refletir um pouco sobre as idéias apontadas por esses estudiosos da linguagem e as condições de produção em que foram desenvolvidas. $O$ primeiro estudioso salienta- se no cenário nacional como o "primeiro lingüista brasileiro" (Naro, 1976, p.85), que buscou pela institucionalização e consolidação da ciência Lingüística no país, em especial na década de 60, época na qual publicou 0 referido trabalho. A segunda estudiosa, que foi aluna de Mattoso Câmara, buscou desenvolver os estudos lingüísticos no Rio Grande do Sul e dedicou-se, especialmente, às pesquisas em descrição lingüística, bem como a estudos que estejam relacionados a essa área, como o trabalho que propomos como leitura.

É interessante salientarmos que, ao longo de sua vida acadêmica, Mattoso Câmara dedicou-se, de forma especial, a estudos em torno da Língua Portuguesa, vindo a publicar a reconhecida obra intitulada Descrição da Língua Portuguesa, e quando faleceu, estava desenvolvendo a obra Estrutura da Língua Portuguesa, que foi publicada posteriormente. Logo, observamos que no desenvolvimento do seu texto, o lingüista posiciona-se como um pesquisador da Língua Portuguesa, que realiza um estudo de possíveis influências em torno do seu objeto. Já Neusa Martins Carson se dedicou a trabalhos em torno de línguas presentes no território brasileiro, que estariam desaparecendo sem deixar registros; e fez, na sua tese de doutorado, uma descrição fonológica e morfossintática de uma língua indígena, o Macuxi. Sendo assim, entendemos que, em seu artigo, a estudiosa se posiciona como uma pesquisadora de línguas "não oficiais", presentes no nosso país.

Uma visualização das posições de tais pesquisadores nos auxilia na compreensão de como são colocados seus pontos de vista sobre as línguas portuguesa e africana, bem como do contato entre essas. Retomamos que a primeira afirmação do lingüista sobre a Hipótese crioulística é que "os escravos negros adaptaram-se ao português sob a forma de um falar crioulo" (Mattoso Câmara, 1963, p.117). Por uma análise deste enunciado, observamos que 0 autor faz referência, inicialmente, ao "Português", língua à qual os escravos teriam se "adaptado" e, posteriormente, coloca a expressão "sob a forma de um falar crioulo". Logo, percebemos a falta de algo em suas palavras: a designação Português crioulo. Por que Mattoso Câmara silencia Português Crioulo e em seu lugar coloca falar crioulo? A partir da idéia de que esse silêncio do lingüista "é a matéria significante por excelência" (Orlandi, 1997, p. 31), buscaremos refletir sobre qual a posição do lingüista frente a existência ou não de um Português Crioulo no Brasil. 
Aliado à estrutura de tal enunciado, em relação ao lingüista da Língua Portuguesa, quando se trata do contato dessa com a língua africana, observamos a seguinte afirmação: "a influência do português crioulo, de que em princípio não se pode abrir mão, só pode ser encarado como um efeito de gatilho6" (Mattoso Câmara, 1963, p. 118). Nesta passagem, temos a presença de português crioulo seguido da expressão de que em princípio não se pode abrir mão. Isto nos leva a novos questionamentos: por que Mattoso Câmara rompeu o silêncio de português crioulo? Por que não pode abrir mão de tal enunciado?

Já no texto de Carson, que é iniciado com um levantamento de dados históricos sobre a chegada e a presença de africanos no Brasil, durante o século XIX, é posta a afirmação de que "não há evidência de que o contato das línguas africanas com o português tenha provocado uma alteração violenta e inesperada na língua portuguesa". (p.123). Esta colocação vai ao encontro de uma colocação de Mattoso Câmara de que "não se dariam mudanças fonológicas e gramaticais profundas sem correspondência com as próprias tendências estruturais da língua portuguesa" (p.118). Por tais enunciados, entendemos que Carson começa seu texto, definindo um posicionamento contrário a uma Hipótese crioulística, enquanto que Mattoso Câmara, no desenvolvimento de seu trabalho, posiciona-se de uma forma que possibilite, pelo seu discurso, isentar a Língua Portuguesa de ter sofrido mudanças, as quais já não estivessem predispostas, pela estrutura lingüística do Português, a se desenvolverem. Utilizamos da metáfora de Orlandi a seguir, para refletir sobre a posição de Mattoso Câmara.

Como para o mar, é na profundidade, no silêncio, que está o real do sentido. As ondas são apenas o seu ruído, suas bordas (limites), seu movimento periférico (palavras). (Orlandi, 1997, p.35)

O referido artigo de Mattoso Câmara, que foi desenvolvido na década de 60 , ainda estava muito próximo aos anos que tivemos um apogeu dos estudos em torno de uma existência de um Português crioulo no Brasil. Segundo Alkmim (2005), "as discussões sobre o tema tinham perdido muito do interesse alcançado nos anos 1930 1940", e talvez por

\footnotetext{
6 Grifo do autor.
}

isso, "a posição de Mattoso tenha permanecido à margem" (p.113). Esta observação que Alkmim nos coloca sobre o fato de Mattoso Câmara ter permanecido à margem, às bordas, à superfície, em função do tema não estar tão em voga quanto em outras décadas, para nós emerge justamente como uma tentativa de rompimento com uma tradição anterior. Esta, mesmo já tendo perdido muito do interesse, ainda se presentifica pelas marcas deixadas por "teóricos oficiais", pela memória, podendo silenciar tentativas de rompimento ou fazer falar tentativas de silenciamento. Os ruídos provocados pelas tentativas de falar e/ou calarse não trazem um posicionamento constituído em relação à problemática em questão. Apenas colocam a possibilidade de que ela exista, imersa na profundidade, onde está o real do sentido.

A lingüista Neusa Carson, já mais distanciada, aponta exemplos posicionando-se contra tal hipótese como o que salientamos sobre os deslocamentos morfossintáticos do pronome ele, os quais, conforme comprovado pela pesquisadora, já apareciam na literatura portuguesa arcaica do século XVI, e não seriam evidências de um falar crioulo.

Seguindo na mesma direção, Mattoso Câmara, no seu trabalho, afirma que construções em que ele aparece como acusativo não resulta de influência de línguas africanas e que "o português europeu arcaico praticou a invariabilidade de ele como recurso estilístico, o que prova que não se trata de um traço de profunda natureza estrutural" (p.122). Para o lingüista, como já salientamos, "uma língua nunca se acha fixada e não há língua unitária e fixa". No caso da língua portuguesa, tais mudanças são constitutivas de nossa língua, conforme podemos observar nas palavras de Mattoso Câmara, sobre o caso do pronome ele.

Eu já mostrei alhures que se trata de uma inovação que estava prefigurada no sistema gramatical português e que no Brasil, em novas condições lingüísticas estruturais e sociais -, encontrou um ambiente favorável para se desenvolver. (Mattoso Câmara, 2004, p. 118) ${ }^{7}$

A partir disso, buscamos refletir sobre o deslocamento de uma língua, de um espaço

\footnotetext{
7 Nota do autor: Ele comme um accusatif dans le portugais du Brésil. Miscelânea Homenaje a André Martinet.
} 
cultural a outro espaço, com outra cultura. Temos uma língua que atravessou o Atlântico e, quando colocada em um novo espaço lingüístico-cultural, acaba desdobrando-se, historicizando-se, fazendo-se presente no novo ambiente. Isto possivelmente se dá devido à relação da Língua Portuguesa com a diversidade cultural e a presença de diferentes línguas no nosso país. Tanto em trabalhos de Neusa Carson, como de Mattoso Câmara, temos apontamentos sobre a relação entre língua e cultura. $\mathrm{O}$ segundo, em sua primeira obra, Princípios de lingüística geral, afirma que "a língua depende de toda a cultura, pois tem de expressá-la a cada momento. É o resultado de uma cultura global" (Mattoso Câmara, 1969, p.21). Já a primeira, em um trabalho intitulado Relações SemânticoSintáticas em Macuxi, coloca-nos que "toda a língua está integrada com a cultura em que opera e a língua expressa em sua estrutura aquilo que interessa diretamente a um grupo social". (CARSON, 1979, p.54).

Sobre a relação entre a língua e a cultura portuguesa com a língua e a cultura africana, ambos os lingüistas salientam que a relação entre os sujeitos de diferentes línguas se deu num espaço cultural propício para movimentos discursivos, conforme observamos pelas palavras de Mattoso Câmara.

\begin{abstract}
Os escravos negros adaptaram-se ao português sob a forma de um falar crioulo. Nos latifúndios, ou fazendas, da época colonial e do Império o contato foi intenso e estreito. As crianças eram confiadas aos cuidados de amas escravas [...]. É claro, entretanto, que não se dariam mudanças fonológicas e gramaticais profundas sem correspondência com as próprias tendências estruturais da língua portuguesa. (Mattoso Câmara, 1975, p.77).
\end{abstract}

Acerca dessa observação de Mattoso Câmara, temos em Neusa Carson a afirmação de que desse contato das crianças com as amas, ou cozinheiras, tornou-se inevitável a presença de palavras de origem africana em nossa língua. De acordo com a lingüista, "existem, de fato, numerosos vocábulos de origem africana no português, especialmente em áreas culturais da culinária, religião e instrumentos musicais" (CARSON, 1979, p.123).

Nesse sentido, finalizaríamos colocando que o lingüista Mattoso Câmara, na sua posição de estudioso da Língua Portuguesa, num período em que estava se constituindo como uma referência nacional nos estudos lingüísticos, mas ainda não era reconhecido como um "teórico oficial", discursiviza uma posição contrária a dos cânones da época. Já a lingüista rio-grandense, em uma década posterior, retoma a posição do mestre, bem como se constitui como uma lingüista e especialista em descrição de línguas presentes no território, estudos que Mattoso Câmara aponta como necessários aos trabalhos em lingüística no país.

\section{REFERÊNCIAS BIBLIOGRÁFICAS}

ALTMAN, Cristina. A Pesquisa Lingüística no Brasil (1968-1988). São Paulo: Humanitas/FFLCH/USP, 1998.

ALKMIM, Tânia. A "Hipótese Crioulistica" de Mattoso Câmara para o Português do Brasil. In. Revista Estudos da Língua(gem) Mattoso Câmara e os Estudos Lingüísticos no Brasil. n. 2. Bahia: Vitória da Conquista, 2005.

CARSON, Neusa M. O Português do Brasi: um Crioulo? In: Revista do Centro de Artes e Letras. Santa Maria, 1979 (p. 117-123).

Relações semântico-Sintáticas em Macuxi. In: Revista Letras de Hoje. Porto Alegre: PUC/RS, 1979 (p. 53-62).

MATTOSO CÂMARA Jr, Joaquim. Princípios de Lingüística geral. 4 ed. Rio de Janeiro: Livraria Acadêmica, 1969.

Lingüística Brasileira. Trad. $\mathrm{M}^{\mathrm{a}}$ Cândida Bordenave. In: NARO, Anthony Julius (Org.). Tendências Atuais da Lingüística e da Filologia no Brasil. Rio de Janeiro: Livraria Francisco Alves Editora S. A., 1976.

Línguas Européias de Ultramar: 0 Português do Brasil. In: UCHÔA, Carlos Eduardo Falcão (Org.) Dispersos de J. Mattoso Câmara Jr. 3 ed. Rio de Janeiro: Lucerna, 2004.

NARO, Anthony J. Tendências Atuais da Lingüística e da Filologia no Brasil. In: NARO, Anthony J. (Org.). Tendências Atuais da Lingüística e da Filologia no Brasil. Rio de Janeiro: Livraria Francisco Alves Editora S. A., 1976.

ORLANDI, Eni P. As formas do silêncio. 4 ed. Campinas: Editora da Unicampo, 1997.

PÊCHEUX, Michel. O Discurso: Estrutura ou acontecimento. Trad. Eni P. Orlandi. Campinas: Pontes, 1990. 
UCHÔA, Carlos Eduardo Falcão. Os estudos e a carreira de Mattoso Câmara. In: UCHÔA, Carlos Eduardo Falcão (Org.) Dispersos de J.
Mattoso Câmara Jr. 3 ed. Rio de Janeiro: Lucerna, 2004. 